\title{
Towards the Development of a Mobile Agriculture System for Poms Poultry Farm (PPF), Oyarifa-Accra, Ghana
}

\author{
Nana Yaw Asabere ${ }^{(\varpi)}$ \\ Accra Technical University, Accra, Ghana \\ nyasabere@atu.edu.gh \\ Amevi Acakpovi \\ University of Johannesburg, Johannesburg, South Africa \\ Vida Kumiwaa Owusu \\ Accra Technical University, Accra, Ghana \\ Jerry Abudu Attah \\ Accra Technical University, Accra, Ghana \\ Eugene Kyeremateng Opoku \\ Accra Technical University, Accra, Ghana
}

\begin{abstract}
This paper seeks to propose the implementation of a mobile agriculture (m-agriculture) system for Poms Poultry Farm (PPF) to solve problems such as low patronage of farm products and customer relationship management among farmers and customers. To corroborate the successful implementation of an m-agriculture system at PPF, we employed a questionnaire research instrument concerning the Technology Acceptance Model (TAM) model as a theoretical framework. Closed-ended questionnaires were administered to a sample size of 130 PPF customers. Based on the responses received, we established optimistic responses towards technological acceptance which paved the way for us to propose and develop a suitable m-agriculture application for PPF. It is envisaged that successful implementation of our proposed system will practically increase productivity and help PPF reach out to their target customers.
\end{abstract}

Keywords-customers, mobile agriculture, Oyarifa-Accra, Ghana, poms poultry farm, technology acceptance model.

\section{$1 \quad$ Introduction}

After gaining independence, Ghana was the world's largest producer of cocoa beans (the main ingredient in the manufacture of chocolate) and boasted of one of the 
highest GDP per capita incomes in the region [1]. Ghana is also involved in both animal production and crop production. The principal crop produce of Ghana can be divided into three subsectors, namely, the industrial crops (which include cocoa, oil palm, coconut, coffee, cotton, kola, rubber, cashew, and shea), the starchy and cereal staples (which include cassava, cocoyam, yam, maize, rice, millet, sorghum, and plantain) and fruits and vegetables (which include the likes of pineapple, citrus, banana, pawpaw, mango, onions, tomatoes, pepper, and eggplant or garden eggs) [2].

The animal products of Ghana can also be summed up as livestock (which includes cattle, sheep, goats, pigs) and poultry (referring to chickens, turkeys, geese, and guinea fowls) [2]. Ghana has abundant viable land and a reasonably well-educated population that can support different types of agriculture including crop production and animal husbandry. Unfortunately, in the last several years, the agricultural sector has been performing poorly and poultry production has unfortunately encountered liberal trade policies that have exposed it to competition from imported products, compelling an almost exclusive focus on egg instead of meat production [2].

The term poultry is used collectively to designate those species of birds that have been domesticated to reproduce and grow in captivity thereby rendering products of economic value [3]. Chickens, turkeys, ducks, and geese generally meet the above criteria. They provide meats, eggs, feathers, animal food, and other by-products such as pharmaceuticals [3]. The poultry industry is perceived to be a major contributor to Ghana's development through employment creation and the enhancement of nutrition and food security. Despite these contributions, the poultry industry is entangled with several challenges that hinder the exploitation of its full potential to the economic contribution [2], [4]. Some of the challenges that farmers encounter include lack of effective customer service, reconciliation of records between farmers and traders, lack of an effective way to collect farm produce data, records farm input expenses, and receive information from other stakeholders [4], [5].

Alternatives to approach such problems are signaled in previous studies. For example, new architectures for poultry houses [6], [7] promote the literal flow and sensor networks technologies collect more reliable samples of climatic conditions inside poultry houses [8], [9]. These novel perspectives suggest that poultry houses could be both architecturally and logically exploited to improve automatic control.

Besides agriculture, ICT and specifically mobile technology have been widely used in other sectors of development especially in developing countries such as Ghana. In such places, mobile technology has been majorly viewed as a reaction to different challenges and different limitations usually infrastructure, poverty, distance, and sparsity [10]. For example, mobile agriculture (m-agriculture) supports the stakeholders in the agriculture value chain through the use of mobile technology. Consequently, the purpose of this study is to determine how activities within Poms Poultry Farm (PPF) at Oyarifa, Accra-Ghana are operationalized and examine the prospects and challenges that confront the awareness and visibility of PPF. Then, we provide a computerized solution by developing an $\mathrm{m}$-agriculture system that will help address the current state of visibility and awareness of services provided by PPF. 
Journal of Digital Food, Energy \& Water Systems, 1 (1): 65-86, 2020

ISSN 2709-4529

(c) Centre for Cyber Physical Food, Energy \& Water Systems

With the aid of the Technology Acceptance Model (TAM) and Mobile Application Development Framework (MADF), this paper employs a quantitative (closed-ended questionnaire) approach to verify and examine the benefits, drawbacks, and implementation of a mobile agriculture application system at PPF. The rest of this paper is structured chronologically as follows: Problem Statement, Literature Review and Related Work, Materials, Methods and Analysis, Discussion and Evaluation of Proposed M-Agriculture System for PPF, and finally Concluding Remarks.

\section{Problem Statement}

Currently, PPF finds it difficult to the awareness of their poultry products to reach out to the general public. This is because only a few people know about them and their poultry products and the physical venue to activate any purchase. Due to the lack of modern technological customer service and customer relationship management (CRM), sometimes PPF needs to give some of their poultry products out freely because they are aging and no one is buying them. As a result of this, PPF has stopped breeding other types of birds such as broilers, turkeys, geese, guinea fowls, etc., and is compelled to focus only on layers that produce eggs. The income of PPF is generated only from the egg production, which does not give rise to enough income/earnings as compared to the selling of the other type of birds which are used as meat. Because of these problems, PPF cannot meet up with the cost being incurred in the breeding of the birds and they soon run into losses as a result of the little income they receive from selling the eggs. Consequently, regarding the advancement of ICT in agriculture, the focus of this paper is aimed at developing an m-agriculture system for PPF to display their products ubiquitously online. This will help them to reach out to the target audience to attract more customers to purchase their poultry products for the generation of more income to boost their business.

\subsection{Research Questions}

To tackle our research problem stated above, we seek to relevantly answer the following research questions below:

- What is the current state of visibility and awareness regarding the services provided to customers by PPF?

- What are the challenges of the current state of visibility and awareness regarding the services provided by PPF?

- What steps are required to improve the identified challenges through the proposal and development of an $\mathrm{m}$-agriculture system for PPF?

\section{$3 \quad$ Literature Review}

In this section, we review the literature and related work about the study. The review concentrated on the following key issues: (i) concept of m-agriculture, (ii) why a 
smartphone over PC (iii) M-agriculture adoption in African Countries, (iv) MAgriculture adoption in Ghana, (v) Challenges in M-agriculture (vi) Benefits of MAgriculture (vii) Theoretical Framework - Technology Acceptance Model (TAM) and (viii) Related Work. Consequently, to achieve our research objectives, the literature review focused on research literature related to mobile agriculture application acceptance and implementation in developing countries. Acceptance and implementation in the context of this study refer to establishing, adopting, and utilizing an magriculture system for accessing poultry-related services.

\subsection{Concept of M-Agriculture}

M-Agriculture is a subset of e-agriculture referring to the delivery of agriculturerelated services via mobile communication technology [10]. Mobile agriculture includes the provision of agricultural services and information, using mobile devices such as cell phones, Personal Digital Assistants (PDAs), tablets, and other handheld communication or computing devices [5], [11]. M-Agriculture also involves gathering relevant data through mobile technologies such as automated weather stations (AWS) or systems and sensors for local-based collections [12]. In recent years, mobile technology has been widely adopted in most parts of the world. Currently, a developing country like Ghana is also recording high mobile penetration rates [13].

\subsection{Smart Phones Versus Desktop PCs}

Mobile computing devices have advantages over the use of a Personal Computer (PC), especially in the developing world [5], [19]. The cost of purchasing a typical smartphone is lower than that of a PC as are the recurring costs. Furthermore, workers in Poms Poultry Farm are conversant with the use of mobile devices than the use of PCs. With these facts, a mobile device is the most appropriate medium to introduce technology to users in Poms Poultry Farm. Moreover, mobile devices provide an environment for interaction between different systems and people. This interaction ensures a more effective and timely way of acquiring information, which is a key requirement in efficient M-Agriculture applications [5], [11].

In many developing countries, more people have access to mobile phones than to older technologies [14]. Many studies have confirmed that mobile phones are indeed improving farmers' production and adoption of new practices [15]. An interview of some Indian farmers and fishermen reviewed that information delivered via their mobile devices allowed them to increase yields [16]. Smartphone coverage has also improved market efficiency and reduced consumer prices for certain commodities [15].

The functionality and flexibility of smartphone use allow marketers and practitioners to implement their marketing strategies efficiently, to accomplish the organizational objectives as well as to ensure good customer services [17], [18]. In the context of our paper, customer service refers to the act of taking care of the poultry needs of customers by providing and delivering professional, helpful, high-quality ICT service and assistance to ensure that the customer's requirements are met. Therefore, the use 
Journal of Digital Food, Energy \& Water Systems, 1 (1): 65-86, 2020

ISSN 2709-4529

(c) Centre for Cyber Physical Food, Energy \& Water Systems

of M-Agriculture application in Poms Poultry Farm might be an important target for mobile marketing.

\subsection{M-Agriculture Adoption in Ghana}

As a result of high smartphone penetration rates in Ghana [39], the modernization of agriculture has been recognized as one of the ways to accelerate Ghana's mediumterm economic development plan. To improve agricultural sustainability and productivity in developing countries, technology adoption by smallholder farmers is a key strategy. Anang [21] therefore investigated the factors influencing the adoption of technology for agricultural mechanization in Ghana. The results indicated farm size, extension visits, herd ownership, the production system, age and gender of the household head, the degree of specialization in production, household size, and location of the farm were significant factors that have to be considered in technology adoption [21].

\subsection{Challenges in M-Agriculture}

According to Minghetti \& Buhalis [23], having access to technology does not necessarily mean that people will use it. Many people have access but are unable to use technology effectively for a variety of reasons. Despite the numerous m-agriculture interventions in different parts of the world, most of them have faced challenges that have rendered them non-impactful in their areas of implementation.

- Technological Challenges: the world of technology is constantly developing and advancing. As mentioned by Verbelen et al. [24], application developers find it difficult to design applications for the mobile market because of the constant improvements that alter mobile devices. Consumers may also find it hard to accept available technologies.

- The Up-Front Investment: required for m-agriculture application solution is larger due to developmental costs. Budgets, finance, accounts, and cash flows will need to be available and negotiated.

- Infrastructure: whether additional technology expenditures can be justified and whether compatibility of all software and hardware can be achieved. Limited network coverage, actual network quality, unreliable SMS due to increasing traffic loads creating network bottlenecks and crippling SMS service, non-existent GPRS and G3 service.

- Handset Limitations: preference for simple, affordable, and low-end phones with small screen-size.

- Language Barrier and High Illiteracy Levels: that play a factor include whether the farmers and consumers are conversant with the use of smartphones, non-literate and semi-literate users of ICT, and plenty of local languages. 


\subsection{Benefits of M-Agriculture}

M-Agriculture applications play a decisive role in vibrant economies as a mechanism that reflects and shapes producer and consumer incentives in supply and demand [25], [26]. The following are some of the advantages of m-agriculture:

- Reachability and Accessibility of Products: is the single most influential factor in adopting m-agriculture. The elimination of costs associated with consumers traveling from their comfort zones to the poultry farm to purchase products and make enquires of the prices of the products. In this case, services and products can be made available to consumers wherever and whenever a need arises [25].

- Consistent Delivery of Products: is possible with Mobile agriculture applications. In this sense, the consumer can place an order in advance for the farmer to make a reservation for that order.

- Information Sharing is one of the advantages of Mobile agriculture applications. With this sense, the farmer can post available products and their prices on the application for consumers. This will facilitate connections between farmers and consumers, thereby creating more efficient markets [27].

\subsection{Related Work}

In this section, we present a review of existing m-agriculture applications in the literature to substantiate the proposal of our m-agriculture application model in PPF.

In Ghana, an m-agriculture platform called Vodafone Farmers' Club (VFC) has implemented an m-nutrition service as well as other mobile services [40]. The mnutrition is a 'bundled solution', offering agriculture and nutrition information through SMS and voice message (provided by Esoko), as well as free calls to others with Vodafone Farmers' Club SIM cards [40].

Gichamba \& Lukandu [5] introduced a model for designing an m-agriculture application for dairy farming. In line with the Agricultural Policy in Kenya [20], their proposed model concentrates specifically on dairy farming and shows how various stakeholders in this sector can share a mobile platform that meets their various needs.

Abhishek et al. [41] developed a mobile application that serves as a platform for the movement of agricultural products from the farms directly to the consumers or retailers. Their mobile and web application provides privilege for both farmers and consumers or retailers to buy and sell required farm products without the involvement of a middleman at its right profitable price.

Łukowska et al. [42] developed an autonomous mobile platform with a soil sampling device for agriculture. In their system, soil samples are analyzed to determine the composition, characteristics, or nutrient levels and the smallholder farmers can use simple hand-held field-testing kits.

Chen et al. [43] developed a system that supports android and IOS system mobile phones, the Widgets technology, and HTTP communication technologies were used to develop a real-time agricultural information collection system, which is based on cross-platform mobile Geographical Information System (GIS). 
Zhang et al. [44] present a Cordova framework based on GeoPackage mobile application to support field operations in agriculture. By implementing GeoPackage Software Development Kit (SDK) on a mobile application, GeoPackage files could easily be accessed, managed, and visualized in agricultural field operations.

Roy et al. [45] developed a system called AgroTick. AgroTick is an innovative hybrid system for smart agriculture that is supported with a mobile interface and designed using IOT technology modules such as cloud computing, embedded firmware, hardware unit, and big data analytics.

Shriram et al. [46] developed a system that provides market information to a farmer using its user-friendly interface on the mobile application. The mobile application is intended to be used for fast and updated information delivering system for farmers. Furthermore, it has native language support to make the transaction easy for farmers.

\subsection{Technology Acceptance Model (TAM)}

According to Oliveira and Martins [28], the Technology Acceptance Model (TAM), is a theoretical model that explains how users come to accept and use technological innovations. Perceived usefulness and ease of use are the major theoretical constructs of the TAM. Chuttur [29] asserted that the perceived usefulness is the extent to which individuals view the benefits of using technology. The Technology Acceptance Model (TAM), predicts how individuals use technology. Additionally, the perceived ease of use is a highlight of how difficult or easy the Technology is, to the user. Thus, a connection exists between these two constructs.

TAM has been used in the context of several studies on user acceptance technology, including the World Wide Web [30], mobile banking, [31] and healthcare [32]. However, along with the relationships suggested by TAM, many researchers have also examined the antecedents of both Perceived Ease Of Use (PEOU) and Perceived Usefulness $(P U)$ [33], [34]. Most importantly, the majority of technology acceptance models have been developed and modified in Western countries, particularly in Europe and South America [35].

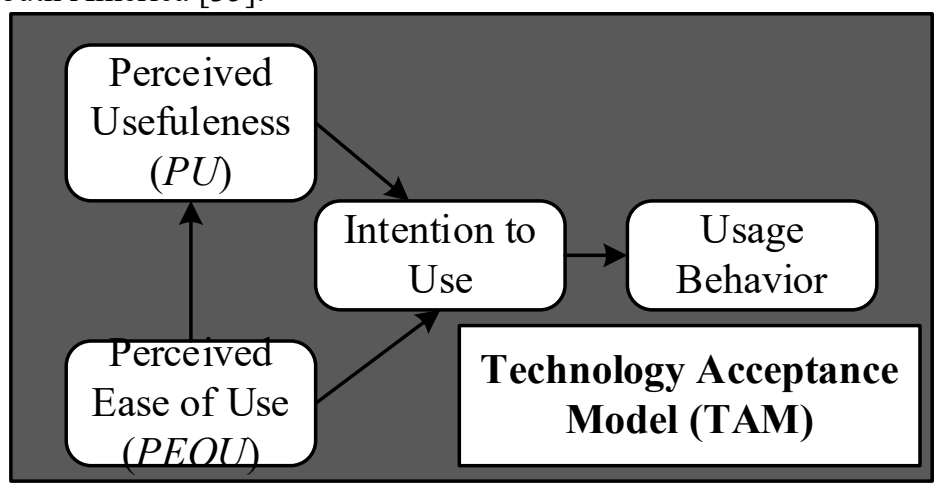

Fig. 1. TAM 
Figure 1 [36], [37], [38] shows the relationship between the components of TAM. This indicates that $P U$ and $P E O U$ jointly predict the attitudes towards using technology. PU also influences the user's Behavioral Intention $(B I)$ or Usage Behavior in using technology. Intention to Use (ITU) also determines the actual use of technology.

With regards to the relationship between PU and Usage Behavior, "within organizational settings, people form intentions toward behaviors they believe will increase their job performance, over and above whatever positive or negative feelings may be evoked toward the behavior per se". Additionally, the model posits that PEOU is likely to influence $P U$, where the increase of $P E O U$ leads to improved performance. Consequently, $P E O U$ has a direct influence on $P U$ [36], [37], [38].

\section{$4 \quad$ Materials and Methods}

In this section, we elaborate on the methodology applied in the research project to gather/acquire the relevant data for effective analysis. Information regarding the population and the sample of the study, research/data collection instruments as well as the results of the study are discussed in this section. This section also elaborates on a detailed analysis of data which provides an insight into the findings of the study, accompanied by numerical representations of the data and interpretation of results.

\subsection{Research Methodology and Data Collection Instrument}

The research methodology adopted for this study was a mixed research approach consisting of quantitative (questionnaire/google forms) and a software development life cycle (SDLC) approach for designing the proposed mobile agriculture application. The questions which constituted the questionnaire were made up of both close-ended and open-ended questions. Furthermore, the questionnaire did not ask the participants to provide any personal details. The quantitative method which involved the administration of questionnaires was selected due to the benefit of reaching out and obtaining more information from a large number of people who are not situated in one place. Figure 2 illustrates the research process of this study.

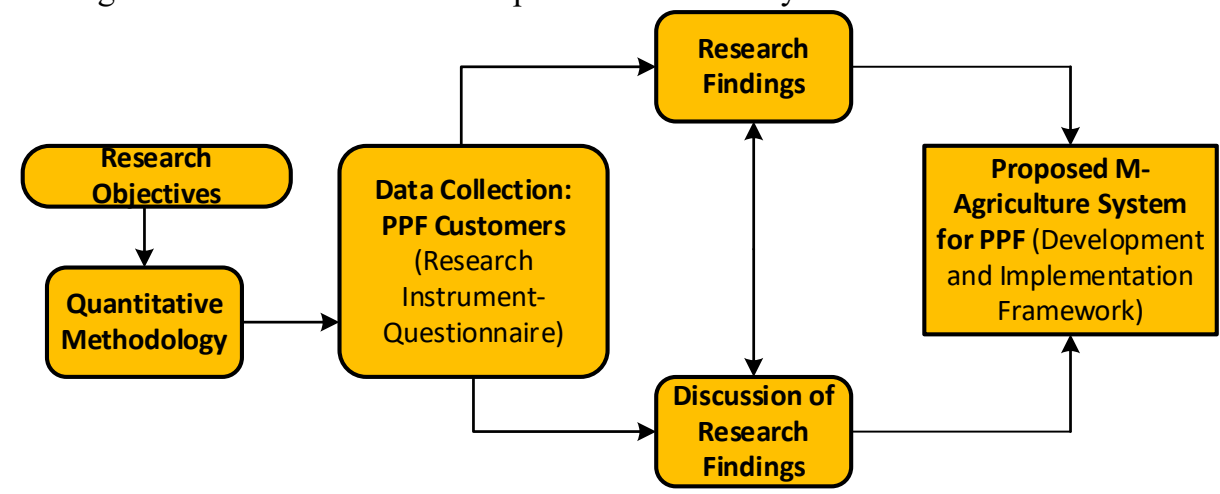

Fig. 2. Research Process 
The questionnaire targeted customers to identify the possibility of adopting technology for an m-agriculture application in Poms Poultry Farm. The questionnaire and field interviews were aimed at collecting information on smartphone devices among the target stakeholders, the usage and experience with general mobile applications, and the usage and experience with m-agriculture applications. The questionnaire consisted of 22 questions in all with three (3) subdivisions consisting of Demography (two questions), Customer/Farmer Information (eight questions), and Technology Acceptance (twelve questions). The questionnaires were distributed to customers electronically through the means of google forms.

\subsection{Population and Sample of the Study}

The participants considered in the study involved customers of PPF. PPF has customers within and outside Oyarifa in Accra (the area that the farm is located). The places outside Oyarifa are Madina and Adenta. The population that was considered were the customers outside Oyarifa because they form the majority of the population size that purchase his products. Customers of PPF were purposively sampled from within and outside Oyarifa. The target population that was initially considered were customers outside Oyarifa from two different places namely; Madina and Adenta. This resulted in a total target population of 130 customers $(\mathrm{N}=130)$. One hundred and thirty (130) questionnaires were administered to the customers. We received one hundred (100) questionnaires from the customers representing a $76.92 \%$ response rate. This response rate shows that we received enough questionnaires for data analysis.

To ensure the reliability and validity of our sample size for customers we utilized a standard formula/equation shown in (1) below from Kothari (2004) as follows:

$$
n=\frac{Z^{2} \times p \times q \times N}{e^{2} \times(N-1)+Z^{2} \times p \times q}
$$

(1)

where $n=$ Sample Size, $Z=$ Confidence Level, $p=$ Probability of Success, $q=1-p$, $N=$ Population and $e=$ Level of Precision. We, therefore, computed our estimated sample size (n) using equation (1). In our computation for $n$, we employed the following in (1), $Z=1.96, p=5 \%(0.05), q=1-0.05=0.95, N=130$ and $\mathrm{e}=0.02$. This computation is shown in equation (2) below.

$$
n=\frac{1.96^{2} \times 0.05 \times 0.95 \times 130}{0.02^{2} \times(130-1)+1.96^{2} \times 0.05 \times 0.95}=\frac{27.37}{0.185}=101.34
$$

The result of equation (2) shows the computation of our estimated sample size as 101.34. However, 1 questionnaire was fully not answered so had to take them off from the total responses received which enabled us to use the remaining 100 as the 
Journal of Digital Food, Energy \& Water Systems, 1 (1): 65-86, 2020

ISSN 2709-4529

(C) Centre for Cyber Physical Food, Energy \& Water Systems

sample size for effective data analysis. Results of the study are presented in descriptive statistics and percentages below.

Table 1. Profile of respondents

\begin{tabular}{|c|c|c|c|c|}
\hline $\mathbf{S} / \mathbf{N}$ & Variable & & Cust & \\
\hline \multirow{3}{*}{1} & \multirow{3}{*}{ Gender } & Category & Number & $\%$ \\
\hline & & Male & 44 & 44 \\
\hline & & Female & 56 & 56 \\
\hline & & Total & 100 & 100 \\
\hline \multirow{6}{*}{2} & \multirow{5}{*}{ Age Group } & $16-25$ years & 41 & 41 \\
\hline & & 26-35 years & 47 & 47 \\
\hline & & $36-45$ years & 12 & 12 \\
\hline & & $46-55$ years & 0 & 0 \\
\hline & & Above 56 years & 0 & 0 \\
\hline & & Total & 100 & 100 \\
\hline \multirow{6}{*}{3} & \multirow{5}{*}{$\begin{array}{c}\text { Highest } \\
\text { Qualification }\end{array}$} & University & 42 & 42 \\
\hline & & WASSSCE & 43 & 43 \\
\hline & & BECE & 4 & 4 \\
\hline & & No Formal Education & 0 & 0 \\
\hline & & Other & 10 & 10 \\
\hline & & Total & 100 & 100 \\
\hline \multirow{4}{*}{4} & \multirow{3}{*}{ Residence } & Oyarifa & 31 & 31 \\
\hline & & Madina & 42 & 42 \\
\hline & & Adenta & 27 & 27 \\
\hline & & Total & 100 & 100 \\
\hline
\end{tabular}

\subsection{Results of the Study}

\subsubsection{Profile of Respondents}

With reference to table 1 above, $44 \%$ (44) of the customers were males and the remaining 56\% (56) were females (Table 3.1). Furthermore, the results in Table 3.1 below shows that majority of the customer respondents in this study were within the age group of $26-35$ as they constituted about $47 \%$ (47) of the total number of customers engaged followed by $16-25$ years representing $41 \%$ (41) followed by $36-45$ years representing $12 \%$ (12).

In terms of qualification of customers, a majority (43) of them hold WASSCE qualification representing $43 \%$. Customers with university qualifications represented $42 \%$ (42), other forms of qualifications constituted approximately $10(10 \%)$ each, and customers with BECE qualification constituted 4\% (4). Also, Table 3.1 shows that majority of the customer respondents reside in Madina representing 42\% (42), followed by customers in Oyarifa representing 31\% (31). Lastly, 27\% (27) of the customers reside in Adenta. 


\subsubsection{Technology Acceptance of Customers of PPF}

The results in Table 2 below displays frequency analysis of the technology acceptance for the customers. Results in Table 2 shows that $95 \%$ representing 95 customers use smartphones and $5(5 \%)$ do not use smartphones. Furthermore, 93 (93\%) customers stated that they use smartphone programs such as games and communication applications. However, 7 (7\%) customers stated that they don't use smartphone programs such as games and communication applications. The results in Table 2 also show that $34 \%$ representing 34 customers are aware of the existence of m-agriculture applications for poultry services and $66 \%$ representing 66 customers are not aware of the existence of m-agriculture applications for poultry services.

Table 2. Technology acceptance by customers

\begin{tabular}{|c|l|c|c|c|}
\hline \multicolumn{2}{|c|}{} & \multicolumn{3}{|c|}{ Customers } \\
\hline S/N & Questions & Category & Number & $\mathbf{\%}$ \\
\hline 1 & Do you own a smartphone? & Yes & 95 & 95 \\
\cline { 2 - 4 } & No & 5 & 5 \\
\hline & \multicolumn{1}{|l|}{ Total } & $\mathbf{1 0 0}$ & $\mathbf{1 0 0}$ \\
\hline 2 & $\begin{array}{l}\text { Do use smartphone programs such as } \\
\text { games and communication applications? }\end{array}$ & Yes & 93 & 93 \\
\cline { 2 - 4 } & No & 7 & 7 \\
\hline 3 & $\begin{array}{l}\text { Do you know whether there is an m- } \\
\text { agriculture application for poultry ser- } \\
\text { vices? }\end{array}$ & Total & $\mathbf{1 0 0}$ & $\mathbf{1 0 0}$ \\
& No & 34 & 34 \\
\hline & Total & $\mathbf{1 0 0}$ & $\mathbf{1 0 0}$ \\
\hline
\end{tabular}

\subsubsection{PEOU of Respondents}

In our study, the Perceived Ease of Use (PEOU) is a highlight of how difficult or easy the technology is, to the user (Chuttur, 2009). As shown in Table 3 below, the highest $\mathrm{M}$ value in terms of PEOU ( $\mathrm{M}=2.31, \mathrm{SE}=0.12, \mathrm{SD}=1.24, \mathrm{~V}=1.53)$ shows that, concerning the responses from customers, they will find the m-agriculture application to be flexible to interact with. This analysis is followed by customers asserting that their interaction with the m-agriculture application would be clear and understandable $(\mathrm{M}=2.26, \mathrm{SE}=0.12, \mathrm{SD}=1.24, \mathrm{~V}=1.55)$. Furthermore, the results in Table 3 shows that, they will find it easy to become skillful at using the m-agriculture application $(\mathrm{M}=2.16, \mathrm{SE}=0.12, \mathrm{SD}=1.19, \mathrm{~V}=1.41)$.

Also, most customers will find it easy to learning how to operate the m-agriculture application $(\mathrm{M}=2.09, \mathrm{SE}=0.12, \mathrm{SD}=1.16, \mathrm{~V}=1.36)$, followed by customers asserting that, they will find the m-agriculture application easy to use $(\mathrm{M}=2.08, \mathrm{SE}=$ $0.11, \mathrm{SD}=1.13, \mathrm{~V}=1.27$ ). Finally, most customers would find it easy to get the $\mathrm{m}-$ agriculture application to do what they want it to do. $(\mathrm{M}=2.00, \mathrm{SE}=0.10, \mathrm{SD}=$ $1.02, \mathrm{~V}=1.04)$.

Table 3. Inferential statistics of the PEOU of customer respondents

\begin{tabular}{|l|c|c|c|c|c|}
\hline PERCEIVED EASE OF USE (PEOU) & TN & M & SE & SD & V \\
\hline
\end{tabular}


Journal of Digital Food, Energy \& Water Systems, 1 (1): 65-86, 2020

ISSN 2709-4529

(C) Centre for Cyber Physical Food, Energy \& Water Systems

\begin{tabular}{|l|c|c|c|c|c|}
\hline $\begin{array}{l}\text { Learning to operate the m-agriculture application would } \\
\text { be easy for me. }\end{array}$ & 100 & 2.09 & 0.12 & 1.16 & 1.36 \\
\hline $\begin{array}{l}\text { My interaction with the m-agriculture application would } \\
\text { be clear and understandable. }\end{array}$ & 100 & 2.26 & 0.12 & 1.24 & 1.55 \\
\hline $\begin{array}{l}\text { I would find the m-agriculture application to be flexible } \\
\text { to interact with. }\end{array}$ & 100 & 2.31 & 0.12 & 1.24 & 1.53 \\
\hline $\begin{array}{l}\text { It would be easy for me to become skillful at using the m- } \\
\text { agriculture application. }\end{array}$ & 100 & 2.16 & 0.12 & 1.19 & 1.41 \\
\hline I would find the m-agriculture application easy to use. & 100 & 2.08 & 0.11 & 1.13 & 1.27 \\
\hline $\begin{array}{l}\text { I would find it easy to get the m-agriculture application } \\
\text { to do what I want it to do. }\end{array}$ & 100 & 2.00 & 0.10 & 1.02 & 1.04 \\
\hline
\end{tabular}

\subsubsection{PU of Respondents}

In our study, Perceived Usefulness (PU) is the extent to which an individual views the benefits of using technology (Chuttur, 2009). As shown in Table 3.4 below, the highest $\mathrm{M}$ value in terms of $\mathrm{PU}(\mathrm{M}=1.84, \mathrm{SE}=0.09, \mathrm{SD}=0.90, \mathrm{~V}=0.80)$ shows that, in relation to the responses from

customers, using an m-agriculture application in poultry activities would enable them to accomplish tasks quickly, followed by customers asserting that Using an $\mathrm{m}-$ agriculture application would enhance their effectiveness in poultry activities $(\mathrm{M}=$ $1.83, \mathrm{SE}=0.10, \mathrm{SD}=0.96, \mathrm{~V}=0.93)$ and the usage of the m-agriculture application will help them to access poultry services quickly $(\mathrm{M}=1.82, \mathrm{SE}=0.10, \mathrm{SD}=0.97, \mathrm{~V}$ $=0.94$ ). Furthermore, the results in table 3.4 shows that, using an m-agriculture application will improve the communication between the farmer and customers $(\mathrm{M}=1.78$, $\mathrm{SE}=0.09, \mathrm{SD}=0.89, \mathrm{~V}=0.80$ ). Also, most customers would find the m-agriculture application very useful in their poultry activities $(\mathrm{M}=1.77, \mathrm{SE}=0.09, \mathrm{SD}=0.90, \mathrm{~V}$ $=0.81)$. Lastly, using an m-agriculture application in poultry services would increase productivity $(\mathrm{M}=1.76, \mathrm{SE}=0.09, \mathrm{SD}=0.93, \mathrm{~V}=0.87)$.

Table 4. Inferential statistics of the PU of customer respondents

\begin{tabular}{|l|c|c|c|c|c|}
\hline PERCEIVED USEFULNESS (PU) & TN & M & SE & SD & V \\
\hline $\begin{array}{l}\text { Using an m-agriculture application would help } \\
\text { to access poultry services quickly. }\end{array}$ & 100 & 1.82 & 0.10 & 0.97 & 0.94 \\
\hline $\begin{array}{l}\text { Using an m-agriculture application would } \\
\text { improve the communication between the farmer } \\
\text { and customers. }\end{array}$ & 100 & 1.78 & 0.09 & 0.89 & 0.80 \\
\hline $\begin{array}{l}\text { Using an m-agriculture application in my poul- } \\
\text { try activities would increase my productivity. }\end{array}$ & 100 & 1.76 & 0.09 & 0.93 & 0.87 \\
\hline $\begin{array}{l}\text { Using an m-agriculture application would en- } \\
\text { hance my effectiveness in poultry activities. }\end{array}$ & 100 & 1.83 & 0.10 & 0.96 & 0.93 \\
\hline $\begin{array}{l}\text { Using an m-agriculture application in my poul- } \\
\text { try activities would enable me to accomplish } \\
\text { tasks quickly. }\end{array}$ & 100 & 1.84 & 0.09 & 0.90 & 0.80 \\
\hline $\begin{array}{l}\text { I would find the m-agriculture very useful in my } \\
\text { poultry activities }\end{array}$ & 100 & 1.77 & 0.09 & 0.90 & 0.81 \\
\hline
\end{tabular}




\subsubsection{Brief Research Discussion}

Regarding the research analysis discussed above as shown in Tables 3 to 4, the respondents (customers) are willing to embrace and accept technology in poultry activities, thereby paving way for us to propose, develop and implement a mobile agriculture application for customers of Poms Poultry Farm.

\section{Proposed M-Agriculture System for PPF}

This section describes the process we utilized to develop the proposed $\mathrm{m}$ agriculture system for PPF. The proposed system was developed and evaluated and the result corresponded with the expected output. Consequently, using the SDLC approach, the proposed system has been developed to ensure that the obligations of PPF as required are met. The software program used in designing the proposed system is based on the PHP-based, client/server type software model. The system is implemented using Bootstrap and MySQL as the backend.

\subsection{System Requirements}

The functional requirements of our proposed m-agriculture application system are:

- The system will enhance effective communication between customers and farmers.

- The system will help increase productivity in the poultry activities.

- The system will allow the Farmer to upload and update products.

- The system will keep records of orders.

In terms of non-functional requirements, our proposed m-agriculture application system successfully runs/operates on mobile devices/ smartphones. Furthermore, our proposed m-agriculture system will be reliable and shall be available within 24 hours every day and can be accessed by both the farmers and customer.

Using the above requirements as well as other features: Application Service (messaging), Utility Services (authentication, user storage, logging and monitoring, application storage, interfacing, and search), and Configuration Services (group management, identity management, and application management), an $\mathrm{m}$-agriculture system shown in Figures 4 to 10 were developed to help both farmers and customers in farming activities and services respectively.

\subsection{Use Case Diagram for Farmers and Customers}

This Use Case Diagram is a graphic depiction of the interactions among the elements of an m-agriculture system. The main actors of this use case diagram are the Administrator/ Farmer and Customers. 


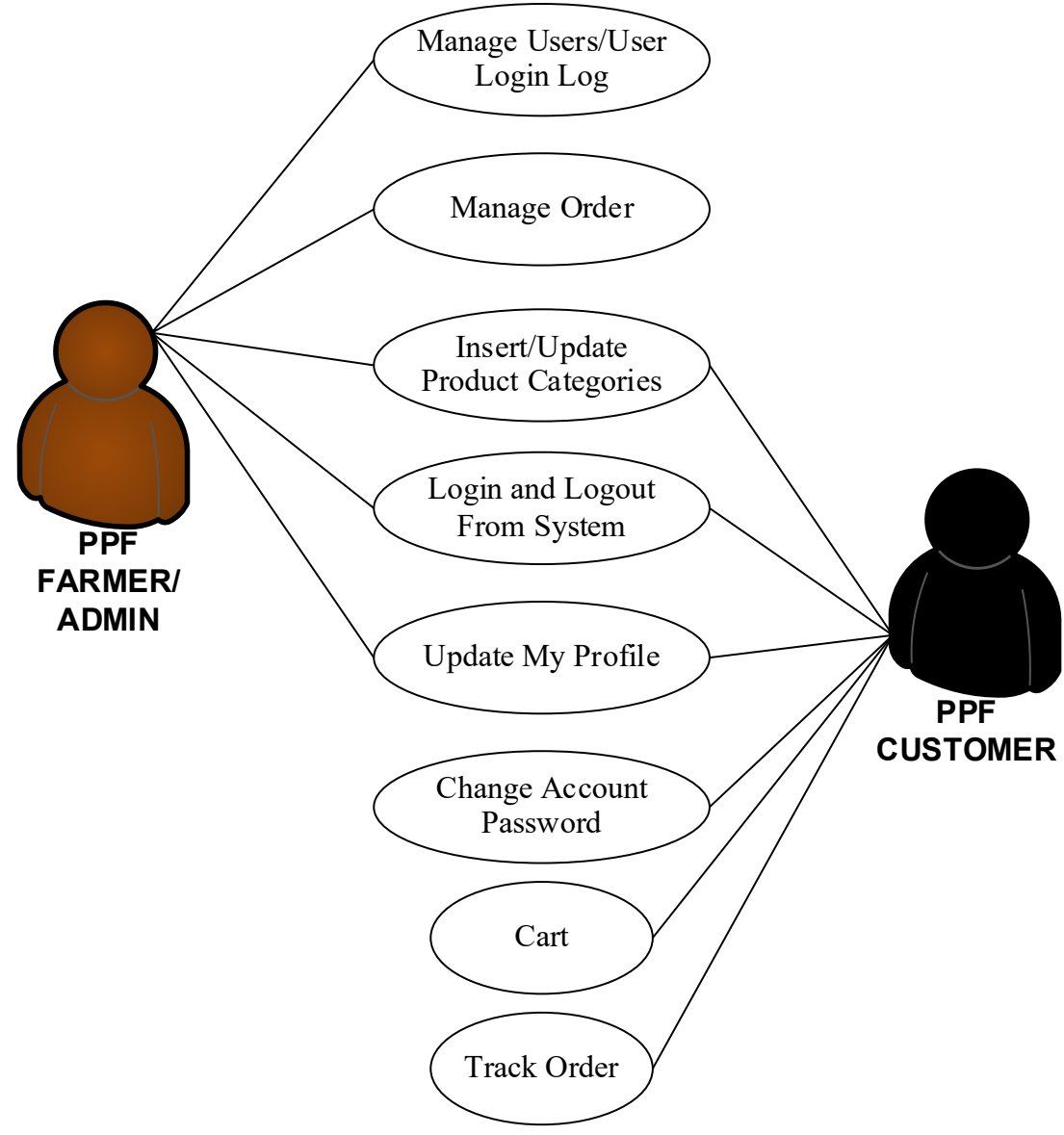

Fig. 3. Use Case diagram for our proposed system

\subsubsection{Administrator/ Farmer}

The administrator/ farmer's relationship among other actors are Manage users, Manage orders, Insert/Update Product Categories.

\subsubsection{Customers}

The customer's relationship among the actors are search product categories, add Products to Cart, Wish List, and Track orders. 
Journal of Digital Food, Energy \& Water Systems, 1 (1): 65-86, 2020

ISSN 2709-4529

(c) Centre for Cyber Physical Food, Energy \& Water Systems

\subsection{Discussion and Evaluation of the Proposed M-Agriculture Application}

Globally, advancements in ICTs have paved the way for the proliferation and beneficial adoption of pedagogic methods in farming activities for both farmers and customers in agriculture. For example, the mobile agriculture application system proposed in this paper, cannot be implemented without both farmers and customers willing to accept and embrace technology as part of farming activities and services in Poms Poultry farm at Oyarifa. Initially, farmers and customers have to go through the normal face to face farming activities which bring about more problems in this process.

Based on the research conducted, the findings revealed that none of the farmers use technology to interact with customers concerning farming activities and products. Furthermore, the findings of the research also revealed that both farmer and customer respondents are strongly willing to embrace mobile agriculture applications and perceive technology as an important tool to improve their farming activities in terms of output quality, patronizing their products, social influence processes, and job significance.

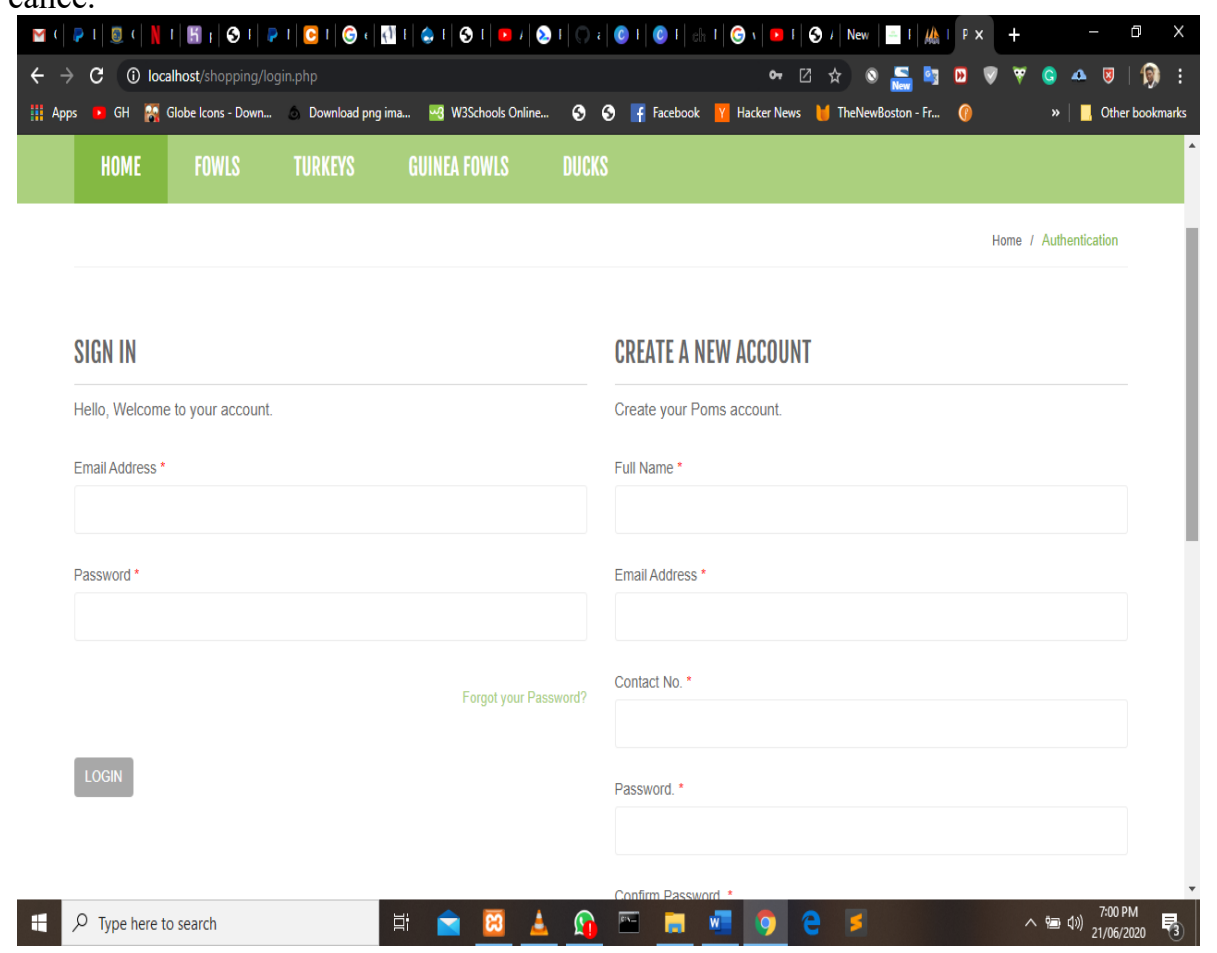

Fig. 4. User login screen 
Journal of Digital Food, Energy \& Water Systems, 1 (1): 65-86, 2020

ISSN 2709-4529

(C) Centre for Cyber Physical Food, Energy \& Water Systems

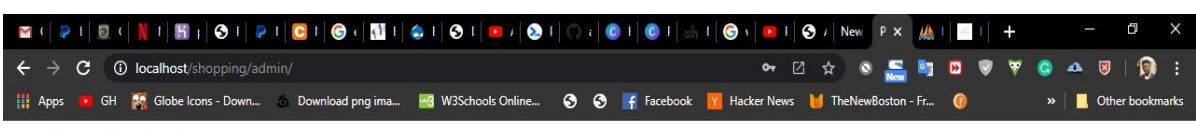

Poms Farm | Admin

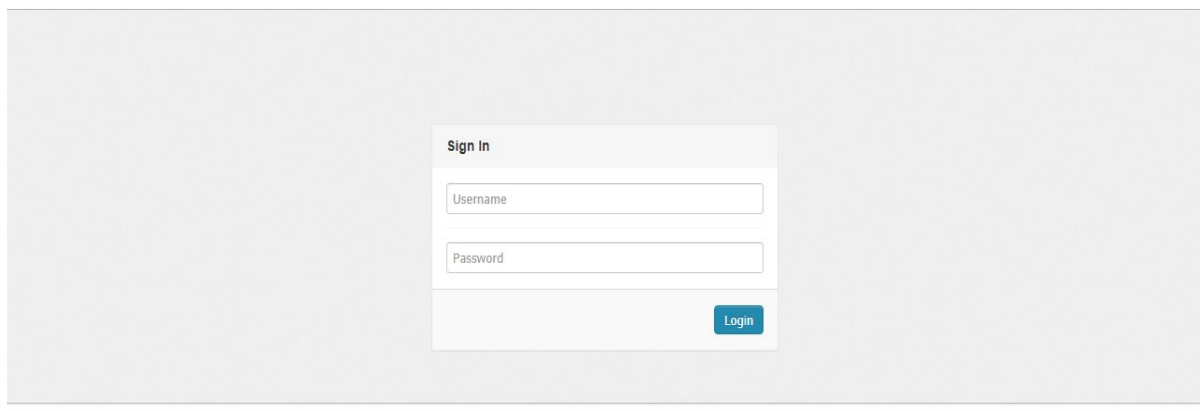

Fig. 5. Administrator/Farmer login screen

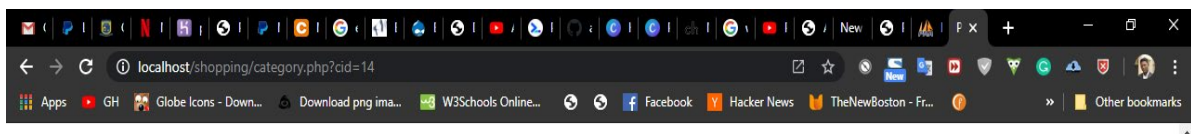

HOME FOWLS TURKEYS GUNEA FOWIS DUCKS

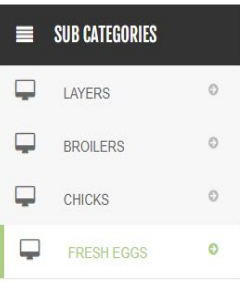

\section{Categary}

FOWLS
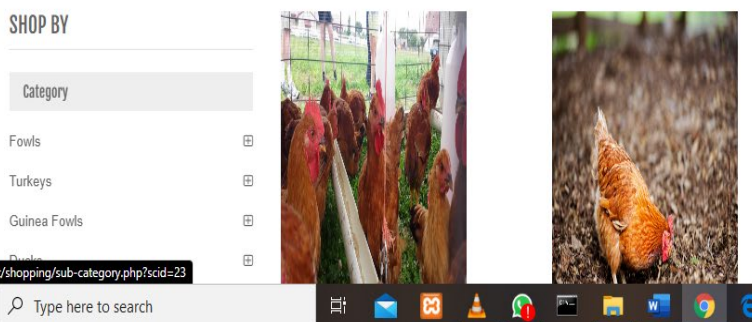

e s 
Fig. 6. Product category

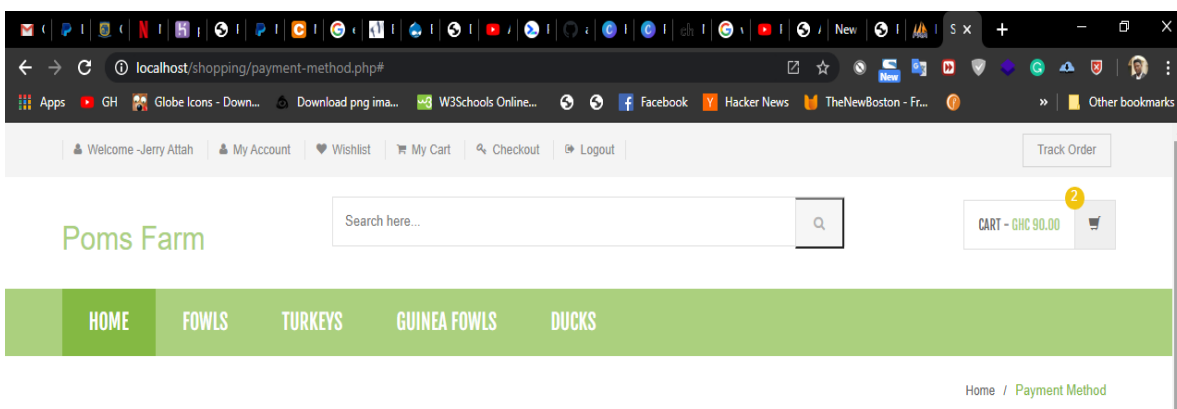

CHECKOUT

SELECT YOUR PAYMENT METHOD

OMobile Money $\bigcirc$ Internet Banking $\bigcirc$ Debit/ Credit card

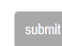

$\rho$ Type here to search

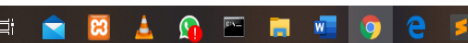

Fig. 7. Checkout page

To successfully develop and implement the m-agriculture application for PPF as proposed in this paper, it was very necessary to review our research questions and ascertain the readiness of farmers and customers in adopting technology as part of farming activities and services. Additionally, it was significant to consider vital variables or needed resources that influence both farmers and customers of PPF to encourage them to use ICT's for farming activities.

The number of farmers and customers used for evaluating our proposed $\mathrm{m}$ agriculture system were five (5) and fifty (50) respectively. In the use of the magriculture application, both farmers and customers agreed that more training in technology usage was needed to effectively implement the proposed $\mathrm{m}$-agriculture system. The proposed m-agriculture system enabled opinions of both farmers and customers to be taken into consideration for effective and successful implementation.

\section{Concluding Remarks}

The fast growth and proliferation of ICT in agriculture have paved the way for technology usage as a tool for farming. This proliferation has enabled agricultural sectors to employ other modes of farming involving ICT such as m-agriculture. To promote and inspire farmers and customers to adopt m-agriculture in PPF, this paper 
utilized a quantitative research methodology (questionnaire), the Technology Acceptance Model (TAM) theoretical framework, and Mobile Application Development Framework (MADF) to propose an m-agriculture system. The questionnaire for this research was developed using components of the TAM and MADF framework. The questionnaire was administered to one hundred and thirty (130) customers in PPF. The proposed m-agriculture system uses smartphone and laptop/notebook features that allow farming to take place anytime and anywhere by PPF farmers and customers through ICT in agriculture.

Similar to the results of previous studies stated in our related work, results of our study revealed that most of the farmer and customer respondents are willing to accept and embrace technology as part of farming in PPF. Additionally, the proposed magriculture system is suitable for integrating ICT in agriculture with the current Faceto-Face (F2F) farming mode in PPF. Furthermore, it is envisaged that judging by the global significance of $\mathrm{m}$-agriculture in agricultural sectors, the proposed $\mathrm{m}$ agriculture system in this paper can also be applied and implemented in other poultry farms in and outside Ghana to further corroborate national international relevance of ICT in agriculture.

A limitation of this research study is the population size concerning the number of customers in PPF as well as other poultry farms in Ghana. To further substantiate the proposed $\mathrm{m}$-agriculture system in this paper, further research, evaluation, and implementation in many other poultry farms in Ghana is very necessary, vital, and relevant. Since this research work is limited to PPF, future work will focus on increasing the population size through the promotion of further research design, amplification, and development of a notebook for the proposed m-agriculture system so that many other poultry farms in Ghana can use it to encourage and motivate their farmers and customers to integrate ICT in agriculture.

\section{$7 \quad$ References}

[1] X. Diao, P. Hazell, J. Thurlow, The role of agriculture in African development, World development 38 (10) (2010) 1375-1383.

[2] S. Haligah, Analyzing production challenges plaguing Ghana's agricultural sector: A focus on poultry production in Greater Accra, Bachelor dissertation, Ashesi University, Ghana.

[3] K. L. Osanyinpeju, A. A. Aderinlewo, O. R. Adetunji, E. S. Ajisegiri, Performance evaluation of a solar-powered poultry egg incubator, International Research Journal of Advanced Engineering and Science 3(2) (2018) 255-264.

[4] I. Augustine, R. Shukla, An analysis of opportunities and challenges in poultry sector in global and Indian perspectives, International Journal in Management and Social Science 3 (1) (2015) 27-35.

[5] A. Gichamba, I.A. Lukandu, A model for designing m-agriculture applications for dairy farming, The African Journal of Information Systems 4 (4) (2012) 120-136.

[6] M. C. Lorencena, L. F. P. Southier, D. Casanova, R. Ribeiro, M. Teixeira, A framework for modeling, control and supervision of poultry farming, International Journal of Production Research, 58 (10) (2020) 3164-3179. 
[7] M. Perkins, N. Correal, B. O'Dea, Emergent wireless sensor network limitations: A plea for advancement in core technologies, In Proceedings of the IEEE International Sensors Conference (2002) 1505-1509.

[8] F. Sallabi, M. Fadel, A. Hussein, A. Jaffar, H. El Khatib, Design and implementation of an electronic mobile poultry production documentation system, Computers and Electronics in Agriculture, 76 (1) (2011) 28-37.

[9] A. G. Soldatos, K. G. Arvanitis, P. I. Daskalov, G. D. Pasgianos, N. A. Sigrimis, Nonlinear robust temperature-humidity control in livestock buildings, Computers and Electronics in Agriculture 49 (3) (2005) 357-376.

[10] S. Deb, Effective distance learning in developing countries using mobile and multimedia technology, International Journal of Multimedia and Ubiquitous Engineering 6 (2) (2011) $33-40$.

[11] S. A. Kumar, C. Karthikeyan, Status of Mobile Agricultural Apps in the Global Mobile Ecosystem, International Journal of Education and Development using Information and Communication Technology 15 (3) (2019) 63-74.

[12] F. Brugger, Mobile applications in agriculture, Syngenta Foundationx 2 (3) (2011) 1-38.

[13] A. Sey, 'We use it different, different': Making sense of trends in mobile phone use in Ghana, New Media \& Society 13 (3) (2011) 375-390.

[14] J. C. Aker, Dial "A" for agriculture: A review of information and communication technologies for agricultural extension in developing countries, Agricultural Economics 42 (6) (2011) 631-647.

[15] G. Tadesse, G. Bahiigwa, Mobile phones and farmers' marketing decisions in Ethiopia, World Development 68 (2015) 296-307.

[16] S. Mittal, S. Gandhi, G. Tripathi, Socio-economic impact of mobile phones on Indian agriculture, (No. 246) (2010) Working paper.

[17] C. Watson, J. McCarthy, J. Rowley, Consumer attitudes towards mobile marketing in the smartphone era, International Journal of Information Management 33 (5) (2013) 840849.

[18] P. Kotler, K. L. Keller, Marketing management, (2016) England: Pearson.

[19] W. Easterly, R. Levine, Africa's growth tragedy: policies and ethnic divisions, The Quarterly Journal of Economics 112 (4) (1997) 1203-1250.

[20] P. O. Alila, R. Atieno, Agricultural policy in Kenya: Issues and processes, (2006) Nairobi: Institute of Development Studies.

[21] B. T. Anang, Farm technology adoption by smallholder farmers in Ghana, Review of Agricultural and Applied Economics (RAAE), 21 (1340-2018-5179) (2018) 41-47.

[22] I. Barnett, S. Batchelor, L. Billings, B. Faith, D. Gilligan, J. Gordon, ... J. Sharp, External evaluation of mobile phone technology-based nutrition and agriculture advisory services in Africa and South Asia, (2019) Ghana Mixed Methods Baseline Report.

[23] V. Minghetti, D. Buhalis, Digital divide in tourism, Journal of Travel Research, 49 (3) (2010) 267-281.

[24] T. Verbelen, T. Stevens, P. Simoens, F. De Turck, B. Dhoedt, Dynamic deployment and quality adaptation for mobile augmented reality applications, Journal of Systems and Software, 84 (11) (2011) 1871-1882.

[25] K. Siau, E. P. Lim, A. Shen, Mobile commerce: Promises, challenges and research agenda, Journal of Database Management (JDM) 12 (3) (2001) 4-13.

[26] S. Balasubraman, R. A. Peterson, S. L. Jarvenpaa, Exploring the implications of mcommerce for markets and marketing, Journal of the Academy of Marketing Science, 30 (4) (2002) 348-361. 
[27] E. Bornman, The mobile phone in Africa: has it become a highway to the information society or not? Contemporary Educational Technology, 3 (4) (2012) 278-292.

[28] T. Oliveira, M. F. Martins, Literature review of information technology adoption models at firm level, Electronic Journal of Information Systems Evaluation 14 (1) (2011) 110.

[29] M. Y. Chuttur, Overview of the technology acceptance model: Origins, developments and future directions, Working Papers on Information Systems 9 (37) (2009) 9-37.

[30] D. G. Mugo, K. Njagi, B. Chemwei, J. O. Motanya, The technology acceptance model (TAM) and its application to the utilization of mobile learning technologies, Journal of Advances in Mathematics and Computer Science 20 (4) (2017) 1-8.

[31] F. Munoz-Leiva, S. Climent-Climent, F. Liébana-Cabanillas, Determinants of intention to use the mobile banking apps: An extension of the classic TAM model, Spanish Journal of Marketing-ESIC 21 (1), (2017) 25-38.

[32] R. M. Abbas, N. Carroll, I. Richardson, In Technology We Trust: Extending TAM from a Healthcare Technology Perspective, In Proceedings of the IEEE International Conference on Healthcare Informatics (ICHI) (2018) 348-349.

[33] C. E. Porter, N. Donthu, Using the technology acceptance model to explain how attitudes determine Internet usage: The role of perceived access barriers and demographics, Journal of Business Research 59 (9) (2006) 999-1007.

[34] J. Yu, I. Ha, M. Choi, J. Rho, Extending the TAM for a t-commerce, Information \& Management 42 (7) (2005) 965-976.

[35] A. Al-Adwan, A. Al-Adwan, J. Smedley, Exploring students' acceptance of e-learning using Technology Acceptance Model in Jordanian universities, International Journal of Education and Development using ICT 9 (2) (2013) 41-55.

[36] F. D. Davis, Perceived usefulness, perceived ease of use, and user acceptance of information technology, MIS Quarterly 13 (3) (1989) 319-340.

[37] F. D. Davis, R. P. Bagozzi, P. R. Warshaw, User acceptance of computer technology: a comparison of two theoretical models, Management Science 35 (8) (1989) 982-1003.

[38] V. Venkatesh, F. D. Davis, A theoretical extension of the technology acceptance model: Four longitudinal field studies, Management Science 46 (2) (2000) 186-204.

[39] Mobile penetration rates in Ghana (2010-2020), Available [Online] at https://www.statista.com/statistics/779708/mobile-connection-penetration-rate-ghana/, accessed 26/12/220.

[40] A mobile agriculture service by Vodafone Ghana, Available [Online] at https:/www.gsma.com/mobilefordevelopment/wp-content/uploads/2017/06/farmersclub-mobile-agriculture-service-vodafone-ghana.pdf, accessed 26/12/220.

[41] A. G. Abishek, M. Bharathwaj, L. Bhagyalakshmi, Agriculture marketing using web and mobile-based technologies, In Proceedings of the IEEE International Conference on Technological Innovations in ICT for Agriculture and Rural Development (TIAR) (2016) 41-44.

[42] A. Łukowska, P. Tomaszuk, K. Dzierżek, Ł. Magnuszewski, Soil sampling mobile platform for Agriculture 4.0, In Proceedings of the $20^{\text {th }}$ IEEE International Carpathian Control Conference (ICCC) (2019) 1-4.

[43] X. Chen, J. Zhao, J. Bi, L. Li, Research of real-time agriculture information collection system based on mobile GIS, In Proceedings of the $1^{\text {st }}$ IEEE International Conference on Agro-Geoinformatics (Agro-Geoinformatics) (2012) 1-4.

[44] C. Zhang, Z. Sun, G. Heo, L. Di, L. Lin, Developing a GeoPackage mobile app to support field operations in agriculture, In Proceedings of the $5^{\text {th }}$ IEEE International Conference on Agro-Geoinformatics (Agro-Geoinformatics) (2016) 1-4. 
[45] S. Roy, R. Ray, A. Roy, S. Sinha, G. Mukherjee, S. Pyne, .....S. Hazra, IoT, big data science $\&$ analytics, cloud computing and mobile app-based hybrid system for smart agriculture, In Proceedings of the $8^{\text {th }}$ Annual IEEE Industrial Automation and Electromechanical Engineering Conference (IEMECON) (2017) 303-304.

[46] P. Shriram, S. Mhamane, Android App to Connect Farmers to Retailers and Food Processing Industry, Proceedings of the 3rd IEEE International Conference on Inventive Computation Technologies (ICICT) (2018) 284-287.

\section{Authors}

Dr. Nana Yaw Asabere received his BSc degree in computer science from Kwame Nkrumah University of Science and Technology (KNUST), Kumasi, Ghana, in 2005, his MSc degree in ICT from Aalborg University, Aalborg, Denmark, in 2010, his Ph.D. degree in computer science from the School of Software, Dalian University of Technology, Dalian, China, in Sep. 2014. He is currently a senior lecturer in the Computer Science Department, and Director of Research, Innovation, Publication and Technology Transfer, Accra Technical University. He has several publications in International Journals and Conference Proceedings. His current teaching and research interests include recommender systems, social computing, and mobile computing. He received the Best Paper Award in the 2013 IEEE International Conference on Ubiquitous Intelligence and Computing (UIC), which constituted part of his Ph.D. research and thesis. He has been a TPC member of all the Workshops on Big Scholarly Data since its inception at the 23rd International Conference on World Wide Web (WWW), 2014. He is a member of IEEE and IEEE Computational Intelligence Society.

Prof. Amevi Acakpovi received the BSc degree in computer and electrical engineering from the Lokossa Institute of Technology (Republic of Benin), in 2006 and the master's degree in electrical engineering option control of industrial process from the Abomey-Calavi University (Republic of Benin), in 2009 and the Ph.D. in Hybrid Energy Systems from the Accra Institute of Technology/Open University of Malaysia in April 2017. He is currently an associate professor and Pro Vice-Chancellor, Accra Technical University, and also Senior Research Associate $-4^{\text {th }}$ Industrial Revolution at the University of Johannesburg, South Africa. He is a scientist and researcher in Renewable Energy Engineering. His research interests include hybrid energy systems, renewable energy development and management, wireless communication, applied electronics, micro-computing, and artificial intelligence. He received the Silver Award in the 2014 International Research Initiative Conference (IRIC) on Innovation in Engineering. He is a member of IEEE and IET-Ghana.

Ms. Vida Kumiwaa Owusu completed her HND in Computer Science at Accra Technical University in 2020. She is currently undergoing her National Service in Accra, Ghana. 
Journal of Digital Food, Energy \& Water Systems, 1 (1): 65-86, 2020

ISSN 2709-4529

(C) Centre for Cyber Physical Food, Energy \& Water Systems

Mr. Jerry Abudu Attah completed his HND in Computer Science at Accra Technical University in 2020. He is currently undergoing her National Service in Accra, Ghana.

Mr. Eugene Kyeremateng completed his HND in Computer Science at Accra Technical University in 2020. He is currently undergoing her National Service in Accra, Ghana. 